\title{
Vaccination Policies and the Principle of Least Restrictive Alternative: An Intervention Ladder
}

\begin{abstract}
The principle of least restrictive alternative (PLRA) states that policymakers have significant reason to implement the policy that is effective in achieving a certain result and that is least restrictive of individual liberty or autonomy. This chapter provides a ranking of vaccination policies, or an intervention ladder, on the basis of the PLRA, assessing the level of coercion of each type of policy. The ranking of vaccination policies I suggest, in order of increasing restrictiveness or coerciveness, is as follows: persuasion, nudging, financial incentives, disincentives (including withholding of financial benefits, taxation, and mandatory vaccination), and outright compulsion. Each type of policy suggestion is presented with a discussion of the level of restrictiveness or coerciveness involved and the potential effectiveness.
\end{abstract}

Keywords Vaccination policy $\bullet$ Restrictiveness $\bullet$ Coercion $\bullet$ Least restrictive alternative

A. Giubilini, The Ethics of Vaccination, Palgrave Studies in Ethics and Public Policy, https://doi.org/10.1007/978-3-030-02068-2_3 


\section{The Principle of Least Restrictive Alternative in Public Health}

In the last chapter, we saw how there is a collective responsibility to realize herd immunity against vaccine-preventable infectious diseases, an individual responsibility to make one's fair contribution to the realization of herd immunity, and an institutional responsibility to implement vaccination policies that at the very least guarantee the realization of herd immunity.

Now, there are different types of vaccination policies that could be successful in realizing herd immunity, depending on factors such as particular socio-economic circumstances or cultural contexts. In order to decide which policy to implement among the potentially effective options, it is commonly acknowledged that policymakers ought to adopt principles of least infringement and of least restrictive alternative.

The principle of least infringement is a central pillar of public health ethics (Childress et al. 2002, p. 173). The principle states that public health authorities, when choosing between available policies for achieving a certain public health goal, should select the health policy that infringes the least upon certain individual rights. Such rights include the right not to be harmed, the right to receive beneficial medical treatments, the right to free movement and association, and the right to bodily integrity and to personal autonomy. In particular, with regard to bodily integrity and limitation of autonomy, which are the two prima facie rights that coercive vaccination policies seem to threaten (either parental autonomy in the case of child vaccination or individual autonomy in the case of competent individual vaccination), the principle of least infringement gives rise to a principle of least restrictive alternative (PLRA) (Childress et al. 2002, p. 173). The PLRA can be stated as follows: "if two interventions can both efficaciously and effectively address a public health or health policy issue and are equal in all other morally relevant respects, the intervention least restrictive of personal liberties ought to be preferred" (Saghai 2014, p. 350). According to Lawrence Gostin, the PLRA requires implementation of the policy that entails "the least intrusion on personal rights and freedoms" whilst being capable of achieving the relevant public health goal (Gostin 2008, p. 142).

In line with the PLRA, the Nuffield Council on Bioethics has formulated an "intervention ladder" that ranks possible public health measures according to their degree of restrictiveness of individual autonomy. At the bottom of the ladder, we find interventions such as providing people with 
information about healthy practices, while at the top, we find maximally restrictive interventions such as restriction of choices (e.g., removing unhealthy ingredients from food) and outright compulsion (Nuffield Council on Bioethics 2007, pp. xviii-xix). In this chapter I will focus on the problem of identifying the least restrictive yet effective alternative for vaccination policies - which, for the moment, I will assume should aim at herd immunity, in accordance with the argument of the previous chapter. The restrictiveness of any type of intervention depends, among other things, on variables such as the psychology of the individuals targeted by a certain public health measure or their socio-economic circumstances. For example, giving financial incentives to parents for vaccinating their children might exert a different influence on the decision-making of different individuals, depending on the extent to which they are in need of money. For some people, an incentive may be impossible to reasonably refuse while others might remain indifferent to the incentive, thus maintaining their autonomy of choice. To give another example, the level of autonomy restriction of mandatory vaccination policies that make vaccination a requirement for enrolling children in public day care or school might depend on whether parents can afford and are willing to pay for home schooling.

The different influence of different possible policies on the decisionmaking of different individuals also suggests that the degree of effectiveness of any policy in achieving a certain public health goal is context-dependent. A systematic review of studies concerning different possible strategies to address vaccine hesitancy concluded that, in order to be effective, strategies should be tailored to the characteristics of the targeted populations, such as the specific reasons for hesitancy and the socioeconomic context (Jarrett et al. 2015). For instance, we can hypothesize that information campaigns would be more effective where parents are concerned about the risks of vaccine side effects on their children, which is one of the most common reasons for vaccine refusal in the US (Salmon et al. 2005), even if, as we will see below, some evidence suggests that information by itself is less effective that one might initially think (Nyhan et al. 2014). In any case, information campaigns are (even) less likely to be effective in the case of vaccine refusals motivated by mistrust in health institutions or health professionals, which is more common in Europe (Yaqub et al. 2014), or in the case of refusal motivated by religious beliefs. Similarly, some forms of nudging, such as vaccinating children at school by 
default and allowing parents to opt out if they so wish, would be more effective where parents do not vaccinate their children merely because of the inconvenience that vaccination normally entails (such as having to pay a visit to the doctor). But, once again, nudging is likely to be less effective in the case of parents with deeply held religious or philosophical beliefs against vaccination, for example, a commitment to "natural" lifestyles (whatever this means). Thus, we would need to adopt different solutions in different contexts in order to find the policy that, consistently with the PLRA, is the least restrictive alternative that is also effective at realizing herd immunity.

Appealing to the PLRA in the case of vaccination policies presupposes the existence of an intervention ladder like the one provided by the Nuffield Council on Bioethics, with specific child vaccination policies ranked from the least to the most restrictive. However, there is a lack of discussion in public health ethics explicitly aimed at providing such a ranking. By contrast, the PLRA has been widely discussed in the context of mental health law and ethics (e.g., Johnston and Sherman 1993; Miller 1982), where the issues addressed have included the permissibility of confining mentally ill individuals in order to protect them and the community at large, as well as whether and to what extent it is permissible to enforce behaviour-changing methods for such individuals. While the aims and scope are different, some lessons might be learnt from the discussion in that field. For example, as Johnston and Sherman (1993) have argued, it is widely acknowledged within mental health law that other, less intrusive procedures must first have been shown to be ineffective before a more intrusive procedure can be implemented (Johnston and Sherman 1993, p. 106). It seems reasonable to suggest that, if we endorse the PLRA, vaccination policies should follow the same logic. Therefore, an intervention ladder based on restrictiveness of different vaccination policies is needed in order to allow policymakers to try different policies starting from the least restrictive ones. This chapter aims to provide just such an intervention ladder for vaccination policies.

Now, one might wonder whether it is even possible to rank vaccination policies according to their restrictiveness. After all, as I have said above, the degree of restrictiveness of different possible policies is contextdependent. Also, what criteria should be used to determine the position on the ladder of any policy? Ideally, given the ineliminable degree of uncertainty, the most plausible answer is that policies should be preferred, other things being equal, if they are (1) likely to be restrictive for the 
smallest population possible and (2) likely to exert the lowest degree of restrictiveness possible for that population. But this answer, by itself, is far from being satisfactory, given that the two criteria might be in conflict with one another. I will address this difficulty in the next section. Having laid the conceptual foundations for my analysis, I will then proceed by introducing the concept of coercion, which can be applied to some types of policies and can be used to assess their level of restrictiveness. After that, I will provide an intervention ladder of possible vaccination policies, each of which is discussed in a separate section of this chapter. I will suggest that public health authorities should take this ladder as a guide for implementing effective vaccination policies in order to comply with the PLRA.

\section{Restrictiveness as Autonomy Violation AND the Criteria for Measuring It}

It seems reasonable to measure restrictiveness of vaccination policies in terms of level of infringement of individual autonomy that a certain policy entails. The reason is that people who are opposed to vaccines or who for any reason do not want to vaccinate themselves or their children often appeal to their autonomy to justify their choice, and they typically oppose vaccination policies that, in different ways and degrees, force them to vaccinate by claiming that such policies infringe upon their autonomy-either bodily autonomy or parental autonomy. While "autonomy" is a philosophically problematic concept, here I will understand autonomy simply as "the control an individual has over his or her own evaluations and choices" (Hausman and Welch 2010, p. 128). This conception of autonomy seems closer to what those who are opposed to vaccines or are sceptical about their benefits claim is violated when they are forced to vaccinate themselves or their children.

We have seen above that there are two criteria for measuring the restrictiveness of possible child vaccination policies. These are the likelihood (1) that a certain policy will be restrictive for the smallest population possible and (2) that the policy would exert the lowest degree of restrictiveness possible, compatibly with a sufficient degree of effectiveness. But the two criteria might be in tension with one another. Policies that are likely to be restrictive, that is, autonomy-infringing, for a greater number of people might infringe upon the autonomy of the affected individuals less than policies that are restrictive for less people. Consider, for example, nudging 
in the form of making school-administered vaccination the default option and giving parents the possibility to opt out. This type of child vaccination nudging could limit the autonomy of a greater number of people than would incentives for vaccinating one's own children. The reason why nudging limits autonomy (understood by its aforementioned definition) is that almost everybody is subject to the same biases that cause one to bypass autonomous and rational decision-making and hence makes nudging effective, as we will see in a later section. By contrast, financial incentives would only restrict the autonomy of the very poorest in society, for whom such incentives would amount to an offer that is simply "too good to refuse". However, the restriction of autonomy exerted by incentives is arguably greater than the restriction of autonomy entailed by nudging, in terms of magnitude of influence on individuals' decision-making. On the one hand, there are offers that the poor might simply find too good to refuse no matter how deeply held their anti-vaccination beliefs are: the influence of incentives on the poor's decision-making in such cases is significant. On the other hand, as we shall see, people with deeply held beliefs against vaccination probably have the cognitive resources to overcome the cognitive biases exploited by nudging. Therefore, they are likely to preserve their capacity for autonomous choice in spite of the nudging.

But how, then, can we rank policies on the basis of their degree of restrictiveness, if the two more plausible criteria for measuring restrictiveness can yield different results? What criterion should be given priority in formulating a ranking that could provide ethical guidance for public policy: the number of people who are likely to experience infringements of autonomy or the degree of autonomy infringement experienced, even if by fewer people?

I propose that we should adopt a combination of the two criteria. More precisely, we should prefer the policy that infringes the least upon the autonomy of any individual, unless the number of people who experience a lesser degree of autonomy violation is sufficiently large to morally outweigh the consideration of the higher degree of autonomy violation that would otherwise be experienced by those who are worse off. In other words, I suggest the adoption of the maximin criterion for the distribution of the burdens of a certain policy, constrained by a utilitarian calculus based on the consideration of the number of people who are burdened by a certain policy. The combination of these two criteria seems in line with some ethical intuitions that most of us would share. Let us see more in details. 
Our purpose is to formulate a ranking that can provide ethical guidance. This means that "restrictiveness" is not only a descriptive but also a normative concept: policies that are less restrictive ought to take priority over policies that are more restrictive. Therefore, when two descriptive criteria for determining the degree of restrictiveness conflict with one another, normative considerations about what ought to be done are relevant in determining what criterion ought to prevail in determining the degree of restrictiveness. The criterion that tells us which policies are less restrictive than others would also tell us which policies are ethically preferable to others. What are these normative considerations?

The two fundamental ethical requirements on which most reasonable people would probably agree seem to be exactly the two criteria mentioned above, namely, that ( 1 ) individuals should be burdened to the lowest degree possible, compatibly with the effectiveness of any given policy, and that (2) the total number of individuals burdened by a certain policy should not be too large. The two criteria can be combined in the sense that there must be some point beyond which, intuitively, the number of individuals burdened is so large that it outweighs the magnitude of the burden experienced by the worse off in terms of autonomy violation. Thus, policies that burden individuals less ought to be preferred to-that is, are to be considered less restrictive than-policies that burden individuals more, unless the number of individuals who are burdened less than others is sufficiently large, in which case the policy that burdens individuals more is to be considered less restrictive and therefore is to be ethically preferred.

For instance, to consider an extreme case, suppose we are choosing between two different policies that will affect one million people. Further suppose that we can measure restrictiveness on a scale $0-100$, where 0 indicates no restrictiveness at all and 100 the highest degree of restrictiveness. Policy A restricts 1 person's choices to a degree of 50 and restricts the choices of 999,999 people to a degree of 0 ; meanwhile, policy B restricts the choices of all 1 million people to a degree of 49 . It seems implausible that we should prefer $B$, even if the burden on any individual in policy $\mathrm{B}$ is lesser than the burden on one individual in policy $\mathrm{A}$. The least restrictive policy is in this case policy A. Thus, my suggestion is that, for our purposes, the least restrictive policy, and therefore the policy that ought to be preferred, is the one that restricts the least the autonomy of those who are worse off in terms of autonomy restriction-according to what Rawlsians would call the maximin rule (Rawls (1971) 1999, 
p. 133) - up to the point at which the number of those who experience some level, even a lower level, of autonomy restriction becomes sufficiently high. It follows that we should care somewhat about fairness in the distribution of restrictiveness across people and somewhat about total restrictiveness (i.e., degree of restrictiveness $\times$ number of people restricted).

However, in ranking possible vaccination policies on the basis of their restrictiveness, we need to have one clear criterion in mind. In what follows, I will adopt the maximin criterion as the primary criterion: I will rank the possible vaccination policies, from least to most restrictive, on the basis of how restrictive they are likely to be for those who are more significantly restricted by the policy in question. (The more precise meaning of "being restricted" will be discussed in the next section.) The choice is motivated not by some specific normative theory, but simply by an intuition I have, and which I think most people would have, when thinking about a fair distribution of certain burdens: it seems to me that we should prioritize placing the smallest possible burden on the worst off and that we should then constrain this criterion only by ensuring that not too many people are significantly burdened in order to protect the worst off. The intuition might be mistaken, but it seems to be supported by approaches to distributive justice that are normally considered reasonable, such as the one based on Rawls' famous "veil of ignorance", adjusted through utilitarian considerations.

The utilitarian constraint means that the maximin criterion I have adopted only provides a provisional ranking. It is understood that, in accordance with the combination of the two criteria, the ranking would have to be modified in case a certain policy that exerts a lower degree of restrictiveness on the worst off is likely to negatively affect (in terms of restrictiveness) a significantly larger number of individuals than a different policy. Thus, for example, incentives can affect the capacity for autonomous decision-making of some individuals more heavily than nudging because, as we mentioned above and as we shall see in more details below, it can be easier to counteract the psychological mechanisms exploited by nudging than it is to resist the temptation to accept an incentive. For this reason, nudging comes before incentives in my intervention ladder. However, in cases where only a very small part of the affected population is in such a poor socioeconomic situation that they cannot refuse incentives, or if the number of people who are affected by nudging is sufficiently large, we would need to change the order and rank nudging after incentives. When and where this is the case depends on factors that are context specific. 
Marcel Verweij and Angus Dawson have proposed that participation in collective vaccination programs (including child vaccination) should be voluntary, unless compulsion is necessary to prevent serious harm (Verweij and Dawson 2004). Voluntary and compulsory vaccinations constitute the two extremes of the ladder, involving the minimum and maximum degrees of restrictiveness, respectively. However, one problem with drawing this type of dichotomy is that, between compulsory vaccination and voluntary vaccination, there is a spectrum of different possible interventions involving different degrees of restrictiveness. For instance, the Italian government recently decided to follow the example of the US in making certain vaccinations mandatory, as complying with vaccination schedules has become a requirement for enrolling children in state-sponsored nurseries or preschools. As we will see more clearly after the discussion in the next section, this is an example of a position involving some coercion, which therefore is more coercive (and more restrictive) than completely voluntary vaccination, whilst being less coercive than outright compulsion: parents remain free not to vaccinate their children, although, in practice, such choice has a cost that constrains their autonomy. Predictably, only some parents would be able to afford private day care, and presumably even fewer would be willing to pay for it even if they could afford it. But in what sense we can say that this policy is somewhat "coercive"? I turn to this question in the next section.

\section{Restrictiveness AND CoERCION}

Before presenting the intervention ladder, it is useful to say something more about coercion, given that some vaccination policies are-or at least are often referred to as-coercive. Since people often claim that it is wrong for a state to coerce them into vaccinating themselves or their children, let us examine what it means for a policy to be coercive and why and to what extent coercion in vaccination policies might be thought to be ethically wrong. The notion of coercion has a long philosophical tradition, and some insights from this philosophical debate can shed light on the conceptual and normative implications of restrictiveness.

Many different definitions of coercion have been proposed in the philosophical literature, and the notion has several different meanings in everyday language (Wertheimer 1989, pp. 185-188). Alas, a comprehensive overview of these definitions and meanings is beyond the scope of this chapter. For the purpose of the present discussion, we can follow those 
authors who define coercion in psychological terms, that is in terms of influence of a certain proposal (or policy) on a person's will (e.g., Frankfurt 1973; Feinberg 1989). More specifically, coercion can be conceived as a condition in which someone is forced to do $X$, for example, vaccinating one's children, in the sense that she is left with "no reasonable choice" or "no acceptable alternative" (Wertheimer 1989, pp. 30, 36-37) but to do $X$ when she would otherwise not choose to do $X$. In other words, in cases of coercion a person's autonomy is infringed upon in a certain specific way, i.e. by making certain choices unreasonable or unacceptable, and by subjecting her will to the will of another (Frankfurt 1973, p. 80), where this "other" might be a state. Coercive interventions thwart autonomy-as I have defined it above- to the extent that they render unreasonable those choices that individuals would otherwise make on the basis of their own evaluation. Importantly, on the account of coercion I endorse, someone could be coerced into doing $X$ not only by a proposal that attaches penalties to not doing $X$-that is, a threat, for example, excluding unvaccinated children from school-but also by a proposal that attaches significant enough benefits to doing $X$ - that is, an offer (Held 1972; Feinberg 1989; Frankfurt 1973), for example, giving very large financial incentives for vaccinating one's children.

Thus, the definition of coercion I have provided differs from "baseline accounts" of coercion. According to these, what is relevant for the definition of "coercion" is the distinction between threats and offers, as defined by prospected changes with regard to a certain baseline. The idea behind baseline accounts is that coercion necessarily involves a threat, and offers can never be coercive (e.g., Nozick 1969; O’Neill 1991; Wertheimer 1989; Beauchamp and Childress 2001, p. 95). According to Nozick, one difference between threats and offers is that only the latter preserve freedom; that is, "when someone does something because of offers it is his own choice, whereas when he does something because of threats it is not his own choice but someone else's" (Nozick 1969, p. 459). This view, however, overlooks the influence on individual decision-making that very appealing offers can have. The account I endorse takes instead such influence into consideration. In some cases, for example, when the recipient desperately needs money, offers can leave the recipient with no reasonable choice but to accept what is offered, for example, a financial incentive, and to comply with the conditions of the offer, for example, vaccinate their children. In this sense, we cannot exclude that a certain offer might constitute a form of seduction (Held 1972) to which it is difficult or impos- 
sible not to succumb, although it is true that generally speaking the degree of coercion would often by much lower in the case of incentives than of penalties.

Also included in the notion of "coercion", as I will understand it, is that insofar as an individual is prevented from exercising her free will and judgement, coercion is pro tanto morally wrong. Accordingly, a moral justification that outweighs the prima facie wrongness of coercion is necessary in order to permissibly implement coercive public policies. One example of countervailing moral justification might be the realization of a public good like herd immunity. Admittedly, its positive value can trump the negative value of infringing upon certain autonomy rights of individuals. To be clear, my position is different from moralized accounts of coercion, according to which a proposal must by definition, in order to be coercive, threaten the recipient with the prospect of a wrongful action (Wertheimer 1989, p. 30) - as in "your money or your life" (where, for fear of stating the obvious, killing is the prospected wrongful action). On these accounts, coercion is prima facie morally wrong independently of the fact that it infringes upon autonomy (although the autonomy infringement in case the recipient accepts the proposal would add to the wrongness of the proposal). Instead, the reason why I consider coercion pro tanto wrong is precisely the fact that it infringes upon autonomy together with the consideration that we have a pro tanto moral reason for respecting individuals' autonomy.

Although coercion certainly makes a vaccination policy restrictive, it is important to point out that a policy can be restrictive without being coercive. The ranking I am going to propose takes into account factors other than coercion, because there are non-coercive ways of restricting individual autonomy: a policy can restrict individual autonomy without leaving individuals with "no reasonable choice" or "no acceptable alternative". In other words, the notion of restrictiveness is broader than that of coercion. For example, someone can be restricted in a non-coercive way if her capacity for autonomous decision-making is circumvented through nudging or by exploiting some cognitive bias. Thus, appeals to the notion of coercion will help us in drafting our ranking only with regard to the relative positions of those policies that are both coercive and restrictive.

Restrictiveness also depends on another factor, unrelated to the degree of coercion or of autonomy infringement, namely, what a person is forced to do. For example, it seems intuitively plausible to say that being coerced to have one's children vaccinated is less restrictive than being coerced to, 
say, donate one's kidney. However, while this consideration is important in a comprehensive conceptual analysis of restrictiveness, it is not relevant for the purpose of compiling a ranking of vaccination policies on the basis of restrictiveness since, with any policy, the autonomy right being restricted remains constant, namely, the right to make autonomous decisions over one's body or one's child health.

In the next sections, I am going to present my proposed intervention ladder. I will introduce and discuss the different possible child vaccination policies from the least to the more restrictive. I will start with the least restrictive non-coercive type of policy, namely, persuasion.

\section{Persuasion}

Let us start with what we might call level zero of restrictiveness or coerciveness: mere persuasion. Some form of persuasion in public health communication, such as education campaigns to promote vaccination uptake, might be deployed to encourage people to vaccinate their children. Persuasion is a type of communication that aims at influencing individuals' behaviour (Rossi and Yudell 2012, p. 192). In the context of public health, persuasion has been defined as a "form of interpersonal influence, in which one person tries to change the attitudes or behaviour of another by means of argument, reasoning, or, in certain cases, structured listening". (Warwick and Kelman 1973, quoted in Faden and Faden 1978, p. 183), or in which "a person comes to believe in something through the merit of reasons another person advances" (Beauchamp and Childress 2001, p. 94).

Despite its being aimed at influencing individual behaviour, a distinguishing feature of persuasion so understood is the fact that it is both non-coercive and non-manipulative. By contrast, manipulation infringes, to a certain extent, upon individuals' autonomy by bypassing their capacity for autonomous decisions (Rossi and Yudell 2012, pp. 193-194). For example, manipulation might use subliminal messages or enlist community opinion leaders as allies in pro-vaccination campaigns (Colgrove 2016 , p. 1316) or, as we shall see in the next section, deploy some form of nudging. Mere persuasion, on the other hand, preserves individuals' autonomy by relying merely on provision of factual information and of reasons for engaging in a certain behaviour. This means that individuals generally maintain the capacity to overcome the influence to which they are subjected. I might be exposed to messages concerning the safety and benefits of vaccines, which provide me with pro tanto reasons to vaccinate 
my children; however, if my anti-vaccination beliefs are deeply held or my anti-vaccination sentiments are strong enough, I would probably maintain my capacity to make an autonomous decision not to vaccinate my children, in spite of such messages. Accordingly, I place persuasion at the bottom of my intervention ladder.

Following Stanley Benn, Faden and Faden (1978, p. 186) use the concept of "persuasion" to refer both to persuasion as we have defined it above and to manipulation. However, they maintain the conceptual distinction between the two by distinguishing between "rational" and "nonrational" persuasion. While the former is based on the strength of substantial arguments, the latter aims at influencing individuals' behaviour by bypassing their capacity for rational thinking, for example, through the manner or style in which the arguments are presented. Contrary to what Faden and Faden (1978, p. 188) argue, non-rational persuasion is not coercive, at least according to the definition of coercion I have provided above, because it is incorrect to say that it leaves individuals "with no reasonable choice" but to pursue a certain course of action. However, even if not coercive, non-rational persuasion is manipulative and fails to protect autonomy of choice. This does not necessarily mean that non-rational persuasion, or manipulation in general, is morally unjustifiable: individual autonomy is only one value among many others in public health. The public interest in having enough individuals vaccinated might justify the circumvention of individual autonomy in order to convince them to opt for vaccination. What matters for the purposes of the present discussion is that non-rational persuasion and manipulation circumvent individuals' rational deliberative process and are therefore more autonomy restrictive than rational persuasion. Thus, if we want to refer to persuasion as a form of public health intervention that lies at the bottom of our intervention ladder, that is, that exerts the lowest degree of restrictiveness possible, we need to refer only to rational persuasion. To introduce yet another equivalent concept, some have referred to what Faden and Faden call rational persuasion by using the term "health education", understood as "any combination of learning opportunities designed to facilitate voluntary adaptation of behavior which will improve or maintain health" (Green 1978). In the case of rational persuasion or education, the autonomy to choose whether or not to vaccinate one's children is preserved.

Whether rational persuasion or education would be effective in keeping child vaccination rates high, or in increasing child vaccination rates in any given context, is an open question. In an experiment, a group of hesitant 
parents were provided with different messages - including both images and verbal information-about the MMR vaccine safety and effectiveness, as well as the risks of the diseases targeted by the vaccine. None of the messages convinced parents to vaccinate their children, and in some cases even reduced vaccination intention and activated a post-hoc rationalization. As Nyhan and colleagues explained: "respondents brought to mind other concerns about vaccines to defend their anti-vaccine attitudes, a response that is broadly consistent with the literature on motivated reasoning about politics and vaccines" (Nyhan et al. 2014, p. 6). Besides, even if certain interventions are successful in increasing confidence in vaccines, it is unknown whether increased confidence has any impact on vaccination uptake (Brewer et al. 2017).

The effectiveness of rational persuasion is likely to depend on the reasons why parents would be inclined not to vaccinate. As we have seen in Chap. 1, the phenomenon of vaccine hesitancy is complex, and in any given cultural or socio-economic context, there might be different predominant reasons why people decide not to vaccinate. These include perception of risk, lack of trust in health professionals, or religious or personal moral reasons (Dubé et al. 2013). As put by the WHO's Report of the SAGE Working Group on Vaccine Hesitancy, "[v]accine hesitancy is complex and context specific, varying across time, place and vaccines. It is influenced by factors such as complacency, convenience and confidence" (WHO 2014, p. 8). Therefore, persuasion might work in certain contexts but not in others. A recent study has shown that in the US 74\% of parents who refused to vaccinate their children believed that vaccines are unnecessary, while $64 \%$ were concerned about possible links between vaccination and autism and/or about the presence of thimerosal in vaccine shots (Hough-Telford et al. 2016) - both of which represent misplaced concerns. An older study showed that $69 \%$ of parents refusing vaccination for their children were concerned that vaccines might cause harm in a more general sense (Salmon et al. 2005). These people seem to be the proper target of persuasion or health education campaigns. However, mere persuasion would probably not be effective in the case of parents with a religious or a philosophical opposition to vaccines. In such cases, policies with a higher degree of influence on individual decision-making might be required in order to realize herd immunity. 


\section{Nudging}

Moving on along our intervention ladder, we find a policy that is also noncoercive and minimally restrictive, although more restrictive than mere persuasion, namely, influencing people's choices through nudges. A nudge is a way of setting up the range of choices that "alters people's behavior in a predictable way without forbidding any option or significantly changing their economic incentives" (Thaler and Sunstein 2008/2009, p. 6).

Nudges exploit certain decision biases and automatic cognitive processes, harnessing them in order to encourage certain behaviours $(\mathrm{Li}$ and Chapman 2013, p. 188). In this way, nudges bypass some of people's deliberative capacities and therefore diminish people's capacity for autonomous decision-making. In other words, nudging is a manipulative strategy (Navin 2017, p. 47; Ploug and Holm 2015; Blumenthal-Barby and Burroughs 2012, p. 5). However, it is not a coercive strategy, since it does not leave individuals with "no reasonable choice" or "no acceptable alternative". In their seminal work on nudging, Richard Thaler and Cass Sunstein use the expression "libertarian paternalism" to describe the ethical framework that justifies the use of nudges. The "libertarian" aspect lies in the idea that people remain free to do what they like, in the sense that all the options remain open to them. The paternalistic aspect "lies in the claim that it is legitimate for choice architects to try to influence people's behavior in order to make their lives longer, healthier, and better" (Thaler and Sunstein $2008 / 2009$, p. 5). Or, we might add, in the case of child vaccination, in order to protect the health of themselves, their children, and of the whole community.

One of the clearest cases of manipulation through nudging is the exploitation of status quo bias, that is, people's a priori preference for the status quo over possible alternatives (Thaler and Sunstein 2008/2009, p. 37). Status quo bias gives rise to a "default effect", that is, "the tendency for decision makers to stick with the default, or the option that takes effect if one does not make an explicit choice" (Li and Chapman 2013, p. 190). An example of the default effect is found in opt-out policies regarding organ donation, where people are presumed to consent to donating their organs after death unless they declare otherwise. Some evidence suggests that where opt-out policies are in place, organ donation rates are higher, thus showing the influence of the default effect on individuals' decision-making (Thaler and Sunstein 2008/2009, pp. 187-188). In the case of vaccination, nudges of this type might prove particularly effective in consideration 
of so-called literal inconsistency which is often found in vaccination decisions: parents with favourable vaccination intentions often do not act upon their intentions (Brewer et al. 2011, 2017). In such cases, nudging vaccination might simply be a way of removing those obstacles-whether psychological, material, or both-that prevent people from implementing their vaccination intentions.

For example, nudges could be implemented so as to exploit some of the very same decision-making biases that explain some people's refusal of vaccination and turn them into psychological mechanisms that orient individuals' choices towards vaccination. Opel et al. (2013) demonstrated the decisive role that the "default effect" plays in vaccination discussion between healthcare providers and hesitant parents in parents' vaccination decisions. In their study, they distinguished between presumptive formats of discussion, that is, formats "that linguistically presupposed that parents would vaccinate, such as declaration that shots would be given (e.g., 'Well, we have to do some shots')" (Opel et al. 2013, p. 3), and participatory formats, that is, formats "that linguistically provided parents with relatively more decision making latitude, such as polar interrogatives (e.g., 'Are we going to do shots today?') and open interrogatives (e.g., 'What do you want to do about shots?'), or ones that presupposed that parents would not vaccinate (e.g., 'You're still declining shots?')" (Opel et al. 2013, p. 3). The authors found that "a larger proportion resisted vaccine recommendations when providers used a participatory rather than presumptive initiation format" ( $83 \%$ vs $26 \%$; $P<0.001$ ) (Opel et al. 2013, p. 4). The authors concluded that "[h] ow providers initiate their vaccine recommendations at health supervision visits appears to be an important determinant of parent resistance to that recommendation" (Opel et al. 2013, p. 6).

But we might think of other ways to exploit the default effect in vaccination decisions. For example, children's vaccination in schools could become the default option. At the moment, in most countries, even when vaccination is a requirement for enrolling children in day care or schools, parents would normally have to actively authorize the vaccination and to pay a visit to the doctor. But by changing the default option, all the children enrolled in day care or school would be vaccinated, for example, by a doctor visiting the institution or by school nurses. Parents would not be asked for explicit consent, but they would be informed and given the option to opt out for their children if they so wish, in line with the idea that nudges should not forbid any option. By doing nothing, parents would be implicitly authorizing the vaccination of their children. 
Some have argued that making the exemption procedure itself particularly burdensome from a bureaucratic point of view-for example, requiring notarization of forms, hand delivery, physician confirmation of information disclosure, and so on-would also represent a form of nudging (Lynch 2016, p. 110). This might be true, but seemingly only up to a point. Part of the concept of nudging is not only that decision makers retain their freedom of choice ( $\mathrm{Li}$ and Chapman 2013, p. 188), but also that no option, including opting out, should be particularly costly for the chooser (Thaler and Sunstein 2008/2009, p. 5; Blumenthal-Barby and Burroughs 2012, p. 3 ).

One might object to the use of nudging by appealing to the Kantian categorical imperative, in its formulation that prescribes one to always treat other people also as ends in themselves and never merely as means. Since nudging would circumvent certain deliberative capacities and thus diminish individual autonomy, it would imply that people are treated not as ends in themselves, which would require respecting their autonomy, but as mere means to benefit other people. Now, it is true that, on a Kantian understanding of "means", nudging would imply treating individuals as mere means. However, there are two considerations that mitigate the wrongness of violating the categorical imperative.

First, nudging would often benefit not only society at large but also individuals who are nudged, given that vaccination offers a very high degree of protection against infectious diseases. Nudging in the interest of the those being nudged would make any limitation of autonomy more morally acceptable than nudging that is solely in the interest of the one doing the nudging (Halpern et al. 2007) or of third parties (such as society at large). If individuals are used as mere means, this will often be to their own benefit as well; and it is at least doubtful that autonomy violation represents such a serious wrong that it cannot be justified even by the large benefit it would entail to the individual in question.

Second, outside of a Kantian framework, but within a very reasonable perspective, whether autonomy is such an important value seems to depend on the extent to which making an autonomous choice in a certain context matters to an individual. If vaccination were the default option, since the possibility to opt out would remain open to them, parents would still be able to make the autonomous choice not to vaccinate their children in cases in which they have a strong enough desire to avoid vaccination, that is, in cases in which making an autonomous decision about vaccination matters to them. By "strong enough desire" I mean a desire that is sufficiently 
strong to overcome automatic cognitive processes, such as the a priori preference for the default option. The autonomy of parents with strong enough beliefs or other attitudes against vaccination would be preserved even if child vaccination were the default option. As explained by Yashar Saghai, there is sufficient psychological evidence to believe that "at least when individuals have strong enough preferences, goals, or beliefs, they are likely to become aware of an anomaly" (Saghai 2013, p. 489), that is, of a discrepancy between their conscious desires and what they are nudged to do. Such awareness would enable them to inhibit the automatic cognitive process that the nudging would otherwise exploit. Nudging would only affect the decision-making of parents with weak and trivial beliefs against vaccination. This group includes, for instance, parents who would otherwise not vaccinate their children because they do not have time, do not want to go through the inconvenience of paying a visit to the doctor, or simply think that their child is healthy enough and there is no need for vaccination. In fact, at least some non-medical exemptions to child vaccination are obtained for reasons of mere convenience. This is suggested by the fact that schoolbased immunization clinics have proven to be effective in increasing the number of fully immunized students (Wang et al. 2014, p. e80). But the violation of autonomy in such cases of weak and trivial preferences for nonvaccination does not seem morally significant. To these parents, making an autonomous choice regarding their children's vaccination is not seen as especially valuable, at least not enough to overcome their automatic processes. Since parents do not oppose child vaccination, nudging them by making vaccination the default option would, although autonomy-infringing, not be autonomy-infringing in a morally problematic way.

\section{INCENTIVES}

So far, I have discussed two strategies that lie at the non-coercive end of the spectrum of possible interventions to promote child vaccination. I have argued that persuasion does not involve any interference with autonomy and that nudging can involve interference with autonomy, but that when the latter does, the interference is not morally problematic. I now turn to examining a third possible strategy that, as I shall argue, is more restrictive than the two examined so far, in that it potentially implies some coercion for at least some individuals. This type of intervention is the provision of financial incentives, or conditional cash transfers (CCTs), for vaccinating oneself or one's children. 
What has been called the "archetypical aim" of CCTs is to make certain options less costly and hence more accessible and salient to individuals (Grill 2017, p. 159). In this section, I am going to discuss what Faden and Beauchamp (1986, pp. 357-58) and Krubiner and Merritt (2017) call "unwelcome" offers. These are offers of incentives for engaging in actions that are in tension with individuals' desires and will. For example, an offer of incentives for vaccinating one's children represents an unwelcome offer for parents who are opposed to vaccination.

Now, provision of CCTs for healthy behaviours, including behaviours that promote public health, raise ethical issues on many levels (Lunze and Paasche-Orlow 2013; Marteau et al. 2009), including the design of CCTs schemes, their implementation, and their possible unintended consequences. Carleigh Krubiner and Maria Merritt have argued that in designing CCT interventions, policymakers should attend five types of considerations. These are the likelihood of bringing about the desired benefits, the risks and burdens involved, the receptivity of the intended beneficiaries and of communities, the attainability of the program (e.g., what kinds of barriers to compliance exist for the beneficiary population), and the indirect impact and externalities (Krubiner and Merritt 2017). Moreover, once implemented, CCT programs raise distinctive ethical issues. These include, among others, the potential of incentives for bribery (paying people to act against their wishes), coercion, paternalism, unfairness (it might be argued that people should not be paid to do what they ought to do anyway), and poor use of scarce financial resources (Marteau et al. 2009). Finally, other concerns arise with regard to the possible unintended consequences of CCTs, such as the "crowding out" of intrinsic motivation (Krubiner and Merritt 2017, p. 170).

For the purpose of this chapter, what matters is the kind of influence that incentives have on individuals' capacity for autonomous decisionmaking. In this sense, incentives, at least when they are sufficiently large, are coercive in a way that persuasion and nudges are not, but they are less coercive than imposing penalties or than compelling people to adopt a certain behaviour. Let us consider these two comparisons in order.

First, sufficiently large incentives are coercive in a way in which persuasion and nudges are not, at least according to the definition of coercion I have adopted. Sufficiently large incentives can undermine the decisionmaking processes of vulnerable individuals, particularly of those on a low income (Voigt 2017; Blumenthal-Barby and Burroughs 2012, p. 2). If these individuals are opposed to vaccination, unwelcome offers of suffi- 
ciently large incentives would provide them with strong reasons and motivation to do what they would rather not do, that is, vaccinate their children. In contrast, nudging, although it circumvents autonomous decision-making, does not provide parents with any reason for vaccinating their children. What makes sufficiently large incentives morally problematic in a way that nudging is not is that, for certain parents, such reasons might be too strong to be disregarded. Thus, sufficiently large incentives can interfere with an individual's capacity for autonomous decisionmaking in a way in which persuasion and nudging cannot, that is, by leaving people with no reasonable choice or no acceptable alternative.

And indeed, as I have mentioned above, according to philosophical understandings of coercion that align with our definition (e.g., Held 1972; Frankfurt 1973), not only threats (i.e., proposals to make a person worse off if the person does not do $X$ ) but also offers (i.e., proposals to make a person better off if the person does $X$ ) can exert a coercive influence on an individual's will, at least when they are sufficiently large. According to Harry Frankfurt, just like a threat, an offer may "arouse in the person who receives it a desire-i.e. to acquire the benefit-which is similarly irresistible. This suggests that a person may be coerced by an offer as well as by a threat" (Frankfurt 1973, p. 79). And as put by Virginia Held, "as an inducement to accept an offer approaches a high level, it approaches coercion proportionately" (Held 1972, p. 57).

Of course, incentives become more coercive in proportion to their size relative to the economic circumstances of the recipient. For example, for the vast majority of people in developed countries, a small incentive of US $\$ 5$ would be minimally coercive and less autonomy-restricting than nudging. In the developed world, even a US\$50 incentive, or an incentive in the form of food or medicine coupons, might not have a significant impact on the decision-making of wealthy parents who are sceptical of vaccine efficacy or safety; however, the same incentive might be irresistible to sceptical parents on a low-income or in low-income countries. With regard to the degree of coercion involved by certain offers, Frankfurt (1973) has argued that when an individual $A$ is dependent on $B$ (another individual or a state) for a certain good (such as money), when $A$ needs the good, and when $B$ offers the good to $A$ exploiting $B$ 's dependence and need, withholding a benefit, such as an incentive, is tantamount to imposing a penalty, that is, an offer is ethically and psychologically equivalent to a threat (see also Faden and Beauchamp 1986, p. 358). This view is quite extreme and ultimately incorrect, because, as I will argue in the next section, penal- 
ties are in an important sense more coercive than offers. However, milder versions of the same claim seem at least plausible: to certain individuals, coercion via significantly large offers is closer to the level of restrictiveness entailed by threats than it is to the level of restrictiveness entailed by persuasion or nudging (although it remains true that small offers might be easier to resist than nudges).

Thus, incentives are the first genuinely coercive form of intervention that we encounter as we move up on the intervention ladder. It is important to point out that coerciveness does not make incentives, all things considered, morally impermissible. It might still be justifiable to coerce individuals for the sake of a public good like herd immunity. However, the positioning of incentives on the intervention ladder after persuasion and nudging provides a pro tanto reason against incentives for vaccinating children-grounded in the PLRA - that is stronger than the pro tanto reason against persuasion and against nudging. Accordingly, assuming our aim is merely to realize herd immunity (and this is a proviso worth remembering, and that I will question in Chap. 4), incentives should be used only when persuasion and nudging turn out to be ineffective in realizing herd immunity and when there are sufficiently strong reasons, such as the public interest in realizing herd immunity, that outweigh that pro tanto reason. As far as coercion and restrictiveness are concerned, incentives are more ethically problematic than nudging or persuasion.

However, at the same time-and this is the second comparison I mentioned earlier-incentives are, other things being equal, ethically preferable to penalties for not vaccinating one's children, because they are less coercive according to my definition of coercion. In the next section, I am going to explain why three different types of penalties are more coercive than incentives.

Now, the relevant question is: are incentives effective? And if not, is it necessary to implement a more coercive type of policy, such as the imposition of penalties? Answering this question is complicated. Different systematic reviews have found conflicting and inconclusive evidence regarding the effectiveness of incentives in boosting vaccination rates, with regard to both child (Wigham et al. 2014) and adult (Lagarde et al. 2007) vaccination. It is difficult to draw general conclusions even regarding the effectiveness of incentives in promoting vaccination uptake in types of socio-economic contexts: conflicting evidence regarding incentives' effectiveness has been found both within high-income (Wigham et al. 2014) and within low- and middle-income (Lagarde et al. 2007; Ranganathan and Lagarde 2012) countries. 
The size of the incentive obviously affects individual responses. A theoretical epidemiological game model based on a questionnaire about people's perceptions of influenza and of vaccines found that, in developed countries, in order to have a sufficient proportion of the population vaccinated against influenza, "providing incentives to encourage vaccination is inevitable" (Yamin and Gavious 2013, p. 2668); the same study found that "socially optimal incentives to the vaccinated individuals should be as high as US\$57" (Yamin and Gavious 2013, pp. 2668-9). But also individual socio-economic background, culture, and religion might determine the extent to which incentives influence parents' decision-making regarding their children's vaccination. For example, parents who are opposed to vaccination for deeply held religious reasons would probably be insensitive to financial benefits. However, someone without any principled opposition to vaccines and from a low socio-economic background might see a financial incentive as a too tempting inducement. For this reason, she might decide to vaccinate their children even if she would otherwise not have done so.

Besides, incentives might determine a "crowding out" of intrinsic motivation for the incentivized option or might cause parents to believe that the incentivized option is uncommon or not in line with social norms, since-so individuals might think-people need to be paid in order to be convinced to choose that option (Gneezy et al. 2011; Grill 2017). It is however worth noting that one of the aforementioned systematic reviews about preschool vaccination uptake in high-income countries that claims to have found insufficient evidence to conclude whether financial incentives are effective (Wigham et al. 2014) included both a study about incentives understood as positive rewards (in the form of cash lottery tickets) and studies about incentives understood as avoidance of penalties (in the form of avoiding the withholding of certain state benefits): the conflicting evidence was found only with regard to the latter type. In fact, the only study included about positive rewards in the form of cash lottery tickets clearly showed that positive rewards, that is, genuine incentives, are effective, yielding a $21 \%$ increase in the number of vaccinations received by preschool children. Similarly, some evidence exists that suggests that incentives might be effective in middle- and low-income countries. For example, a study found that incentivizing child DTP vaccination (diphtheria, tetanus, and pertussis vaccines combined) with food coupons significantly increased vaccination uptake in a low-income area of Pakistan (Chandir et al. 2010). 
Thus, in light of this evidence, we can conclude that financial incentives for vaccinating one's children might be effective, but whether they are is context-dependent and cannot be established a priori.

Where persuasion, nudging, and positive incentives are not effective, other more restrictive and more coercive policies would be required. One such type of policies is, as mentioned above, the imposition of penalties for non-vaccination, which I am going to discuss in the next section.

\section{Disincentives}

From a psychological perspective, the claim that threats of penalties are generally (though, as we will see, not always) more coercive than offers of incentives is supported by the existence of two related phenomena. The first is loss aversion, whereby "losing something makes you twice as miserable as gaining the same thing makes you happy" (Thaler and Sunstein $2008 / 2009$, p. 36). In other words, when individuals have to give something up, such as money in the form of a fine for non-compliance with vaccination requirements, "they are hurt more than they are pleased if they acquire the very same thing" (Thaler and Sunstein 2008/2009, p. 36), for example, if they were to receive the same amount of money as an incentive for vaccinating their children. Loss aversion, in turn, explains the second, related psychological phenomenon known as endowment effect: we tend to value the goods that we already possess more than the goods that we do not possess yet, even if the good in question is the same or if the value of the good is the same (see e.g. Kahneman et al. 1991).

Thus, generally (and why I say "generally" rather than "always" will be clarified below), in virtue of loss aversion and of the endowment effect, threatening to impose a penalty for non-vaccination is more coercive than offering incentives for vaccinating one's children, other things being equal (e.g., the size of the incentive and of the offer is equally significant). In virtue of loss aversion and of the endowment effect, individual will is influenced to a greater extent by threats than by offers, in terms of creation of options that leave individuals with "no reasonable choice" or "no acceptable alternative".

Now, it is true that some authoritative studies have suggested that money, differently from other goods, does not create an endowment effect and loss aversion (Zamir 2015, p. 23; Novemsky and Kahneman 2005). However, other studies clearly show endowment effect and loss aversion generated by money and therefore by the threat of financial penalties. For 
example, a well-known experiment has shown that "framing teacher incentive programs in terms of losses rather than gains leads to improved student outcomes" (Fryer 2013). In this study, teachers were more strongly motivated to perform well if the prospect was losing money for poor performance rather than gaining money for good performance. As the authors of the study concluded, "there may be significant potential for exploiting loss aversion in the pursuit of (...) optimal public policy" (Fryer 2013).

And indeed, one type of public policy that could exploit the same psychological mechanisms is one based on penalties, or disincentives (for the purposes of the present discussion, I will take the two concepts as synonymous). This claim is further supported by the fact that among the two types of vaccination policies we are comparing - those based on incentives and those based on penalties - the difference between gains (incentives) and losses (financial penalties) is not merely a matter of framing, as was the case in the aforementioned teachers experiment; rather, it involves actual gains and actual losses. In the experiment above, teachers were differently influenced in their performance according to whether they perceived to be gaining or losing money, where the latter option exerted stronger influence. In the same way, it seems plausible to assume that parents would be influenced differently in their decision whether to vaccinate their children depending on whether they would receive an incentive for vaccination or would be required to pay a penalty for non-vaccination, where the latter option exerts stronger influence.

This difference between the perception of threats and perception of offers is reflected in the different philosophical and ethical treatment reserved to the two in philosophical discussions. From an ethical standpoint, and indeed within a common-sense perspective, threats are generally considered a bad thing, while offers are generally considered a good thing (Hetherington 1999, p. 211). Besides, as Harry Frankfurt noted, threats are generally thought to require justification, whereas offers are generally not (Frankfurt 1973, p. 83), although this claim is, admittedly, quite controversial (but we can leave the issue aside for the purpose of the present discussion).

One clarification is in order. I have said that threats are generally, rather than always, more coercive than offers. In fact, the actual relative influence of threats and offers on individuals will depends on the size of the prospected penalty or of the prospected benefit. The prospect of a very large incentive might exert a greater influence on many people's capacity for 
autonomous decision-making than the prospect of a very small penalty. Although I have placed penalties after incentives on the intervention ladder, the relative position of penalties and incentives might change when we compare significant incentives with less significant or insignificant penalties. Therefore, large enough incentives should come after small penalties on our intervention ladder, as the former are simply more coercive than the latter. Also, the amount of money that renders an offer coercive is probably not the same as the amount of money that renders a threat coercive. For example, because of loss aversion and endowment effect, an offer of a US\$57 incentive for vaccinating their children might be less coercive for some parents than a threat of a US\$57 penalty for not vaccinating their children. However, an offer of US\$100 might be as coercive as a penalty of US\$57, and an offer of US\$150 might be more coercive than a penalty of US\$57. Thus, we need to bear in mind that the amount of money that makes an offer significant is not necessarily the same as the amount of money that makes a threat significant.

Now, there are three main types of penalties, or disincentives, that can be imposed for non-vaccination. I am going to present them in the next three subsections in order of restrictiveness, starting with the least restrictive and least coercive one.

\section{Withbolding of Financial Benefits}

Let us start with the withholding of financial benefits that the state would otherwise pay to parents. This type of policy has been introduced in Australia through the so-called "no jab, no pay" policy. Parents who do not comply with the recommended child vaccination schedule are no longer entitled to receive childcare benefits from the state. In that context, the policy has turned out to be effective. ${ }^{1}$ However, once again, it is difficult to generalize from a single case. As mentioned earlier, a systematic review (Wigham et al. 2014) concluded that there is insufficient evidence for the claim that denying financial benefits is effective in increasing preschool vaccination uptake. As was the case with financial incentives, the effectiveness of the intervention might depend upon factors such as the

${ }^{1}$ See The Guardian, 'No jab, no pay': thousands immunize children to avoid family payment cuts, 31 July 2016, available at https://www.theguardian.com/australia-news/2016/ jul/31/no-jab-no-pay-thousands-immunise-children-to-avoid-family-payment-cuts. Last accessed 26 May 2017. 
particular socio-economic circumstances or cultural background of the targeted population.

The withholding of benefits is in many respects equivalent to the use of incentives. Most evidently, the financial benefit to which parents would be entitled if they vaccinated their children might be seen as an incentive for having one's children vaccinated. This justifies positioning the withholding of benefits close to incentives on our intervention ladder. However, withholding of benefits comes after and is therefore more restrictive and more coercive than the use of incentives because the withholding of financial benefits is analogous to the enforcement of a penalty with regard to its influence on individual decision-making. The reason is that at least some parents who decide not to have their children vaccinated would probably consider financial benefits to which they would otherwise be entitled as part of their normal baseline. Since at least some would perceive the financial benefit as part of the baseline, at least some of those who decide not to vaccinate their children might perceive the withholding of such financial benefits as a penalty, rather than perceiving the provision of the benefits as an offer. As far as restrictiveness and coerciveness are concerned, the withholding of financial benefits makes people who refuse vaccination not only worse off than they would be if they chose vaccination but also worse off than they probably think they should be. Thus, the withholding of financial benefits would, at least in some people, probably trigger the same loss aversion and the same endowment effect that is triggered by the imposition of financial penalties. Therefore, the withholding of financial benefits would be more coercive and restrictive than the provision of positive incentives, to which people do not think they are entitled. The PLRA implies that benefits should be withheld from non-vaccinating people only if persuasion, nudging, and the provision of incentives turn out to be ineffective in realizing herd immunity from a certain infectious disease.

\section{$\operatorname{Tax}$}

It has been suggested that unvaccinated adults as well as parents who do not vaccinate their children for non-medical reasons should be subject to a financial penalty proportionate to the risk of infection the unvaccinated poses on other people (Clarke et al. 2017). According to the proponents of this view, the degree of risk is a function of the severity of the disease in question and of its morbidity.

Now, "financial penalty" can refer to two different things: either a tax or a legal sanction. The main difference between the two is that in the case 
of a tax, the behaviour which is taxed is legal, while a legal sanction means that the behaviour in question is illegal. When there is a legal sanction on non-vaccination, then vaccination is compulsory. Compulsory vaccination will be introduced in the last section of this paragraph and will be discussed in detail in the next chapter; here, I will briefly focus on the disincentive represented by a tax on non-vaccination. Taxing non-cooperative behaviour towards public goods would both discourage such behaviour and force people to internalize the costs of their failure to cooperatesimilarly to how so-called Pigovian taxes force people to internalize the negative externalities, that is, the costs for society, of certain behaviours (e.g., drinking or smoking).

We can consider taxes for non-vaccination as a more coercive policy than withholding of incentives or financial benefits. As we have just seen, the reason why some people would consider the withholding of certain benefits as more restrictive and coercive than pure incentives is that such benefits might be taken to be part of the baseline that defines the status quo. With respect to such a baseline, withholding financial benefits represents a threat of a penalty and therefore makes the recipient worse off. On the basis of the same psychological account of coerciveness or restrictiveness, the level of coerciveness or restrictiveness people experience would be even greater if the sum of money claimed by the state is money that people actually already possess. With respect to the baseline, that is, the status quo, people would be even worse off after paying a tax than after not receiving a financial benefit. Therefore, the influence on autonomous decision-making exerted by taxes is greater than the influence exerted by the withholding of benefits. According to the PLRA, then, taxation for non-vaccination is a type of policy that should be implemented only if policies based on persuasion, nudging, incentives, or withholding of financial benefits turn out to be ineffective in realizing herd immunity. However, both withholding of financial benefits and taxes represent a form of penalty that is less restrictive and less coercive than the withholding of certain social services and goods, as we are going to see in the next section.

\section{Mandatory Vaccination: Denying Enrolment in School and Day Care}

A third type of penalty is non-financial in nature. Where mandatory vaccination is in place, children who do not comply with recommended vaccination schedules could be barred from enrolling in state schools or day 
care. Mandatory vaccination is enforced in some countries, for example, in the US and in Italy (in the latter case only for children of preschool age). In the remaining of this book, I will adopt the terminological distinction between mandatory and compulsory vaccination (Navin and Largent 2017). In the former case, but not in the latter, parents remain legally free not to vaccinate their children (e.g., by home schooling), although this choice comes at a cost that, as I will argue below, might be unreasonable for parents to choose to bear. This (conditional) freedom explains why mandatory vaccination comes before compulsory vaccination on our intervention ladder. At the same time, the fact that the choice not to vaccinate one's children has certain consequences that even wealthy parents might find extremely costly explains why mandatory vaccination comes after, that is, is more coercive than, withholding of financial benefits and taxation on the intervention ladder. In particular, parents would have to provide home schooling to their children or pay for private education.

Often, conscience clauses in vaccination legislations grant exemptions to this mandate on the basis of parents' religious or philosophical (depending on the legislation) opposition to vaccines. At the moment, all but three states in the US (California, West Virginia, Mississippi) have such conscience clauses in their legislations. Clearly, the existence of conscience clauses might render mandatory vaccination not only completely noncoercive but also ineffective. In this subsection, I will consider only mandatory vaccination that does not allow any conscientious objection, as is the case also in Italy. Where conscientious objection is granted, and especially if the exemption procedure is relatively easy and not burdensome, mandatory vaccination would boil down to, and therefore would not be any more restrictive than, a form of nudging.

Now, mandatory vaccination is similar in one important respect to the withholding of financial benefits that I have discussed in the previous section. Exactly like that policy, mandatory vaccination policies threaten to withhold a certain type of benefits from parents who do not vaccinate their children. However, mandatory vaccination is more coercive than the withholding of financial benefits because the type of good withheld does not have a merely monetary value. In the two cases of financial penalties examined above (withholding of benefits and taxes), people with sufficiently strong reasons against vaccination, a high socio-economic status, or both would have the option to make up financially for their vaccine refusal, perhaps by making great sacrifices if they are poor. But denying their children the opportunity to attend day care or school would impose a cost on 
both the parents (in case they cannot afford or do not want to provide private education) and, more importantly, their children for which it is more difficult, if not impossible, to make up. The cost is not merely financial, as there arguably are benefits associated with attending schools or day care in terms of children's well-being and healthy psychosocial development. Thus, unlike the case of financial penalties or of withholding of financial benefits, parents cannot fully compensate financially for the choice not to vaccinate their children. As a consequence, not only is the range of choices open to them more narrow than in the case of financial incentives or withholding financial benefits; also, and more importantly for the purpose of the present discussion, the choice not to vaccinate one's children would often be unreasonable, given that parents would probably be harming their children by denying them the same education that other children have. Therefore, these parents would often be left with "no reasonable choice" or "no acceptable alternative" but to vaccinate their children. This means that when they have to decide whether to vaccinate their children, they would experience a higher level of coercion than in the case of financial penalties in the form of taxation or withholding of financial benefits, that is, situations in which non-vaccination has a merely financial cost which parents might find reasonable to bear.

As before, the relevant question to ask is whether mandatory vaccination is effective. And once again, answering this question is complicated. In California, one year after the introduction of the legislation requiring all children without medical exemptions to have completed their recommended vaccination schedule in order to be enrolled in day care or school, 95.6\% of kindergarteners ended up immunized for the school year 2016-17, up $2.8 \%$ from the previous year and the highest rate ever recorded in the state (California Department of Public Health 2017). However, a study on the effectiveness of state-level varicella vaccination mandates indicates that "the impact of the mandate is a short-run phenomenon. The importance of the mandate effect relative to the aggregate time trend (...) is cut by more than a half by the fourth year after the mandate and disappears completely approximately six to seven years after the mandate" (Abrevaya and Mulligan 2011, p. 971). Thus, where mandatory vaccination is not or no longer effective, a measure of last resort would be required, as I will briefly explain in the next section. However, as we shall see in the next chapter, there are other reasons in favour of compulsory vaccination policy that do not depend on the ineffectiveness of less restrictive policies to realize herd immunity. 


\section{Compulsion}

By making it illegal to refuse vaccination, compulsory vaccination would be the most restrictive and coercive type of vaccination policy. Compulsory vaccination would probably also be the most effective vaccination policy. In the next chapter, I will make the ethical case for compulsory vaccination, also by criticizing some of the authors who have put forward the idea that vaccination should be compulsory, but who have in the end mitigated their claim by appealing to the PLRA (Pierik 2016; Flanigan 2014).

That vaccination is compulsory means that there are legal penalties attached to non-vaccination. These legal penalties can range from a small fine to incarceration. In the next chapter, I will suggest that a significantly large fine is probably the most appropriate legal penalty for non-vaccination. In terms of costs incurred for non-vaccination, if we assume that the legal penalty should be financial in nature, compulsory vaccination is very similar to taxation for non-vaccination: in both cases we are imposing a financial penalty on those who fail to vaccinate. The difference is that, as I said above, in the case of taxation non-vaccination remains legal, while in the case of compulsory vaccination it is illegal. The difference is relevant because the fact that a certain option is illegal justifies imposing very burdensome legal penalties, while keeping the option legal means that the penalty should ideally remain within a reasonable range, since presumably a citizen should be put in the condition to autonomously choose between two legal options and therefore neither option should result too burdensome. Thus, compulsory vaccination is more restrictive than a tax on nonvaccination because compulsion allows an authority to enforce more substantial penalties that would exert a higher influence on individuals' capacity for autonomous decisions. Besides, the fact itself of breaking the law is likely to represent a strong psychological barrier to non-vaccination, as presumably many people would feel uncomfortable breaking the law and being subject to a legal penalty, which means that their autonomy would be way more affected than in case they were simply taxed. In the next chapter, I will provide an argument for compulsory vaccination.

For the purposes of this chapter, what matters is how compulsory vaccination fares in terms of consistency with the PLRA. Because compulsory vaccination is the most restrictive vaccination policy possible, it can only be consistent with the PLRA if all the other possible alternatives, from persuasion to withholding social goods or services, have proven to be ineffective in realizing herd immunity, and, of course, only if we assume that the only aim of vaccination policies is the realization of herd immunity. Thus, 
the PLRA implies that compulsory vaccination should be a measure of last resort, if what we want is simply the realization of herd immunity.

\section{CONCLUSION}

In this chapter, I have provided an intervention ladder that ranks possible vaccination policies on the basis of their degree of restrictiveness. If we accept that the principle of least restrictive alternative (PLRA) provides a reason to implement the least restrictive policy that is effective in realizing herd immunity, then governments have a reason to test the efficacy of possible policies in the following order, starting from the least to the most restrictive: persuasion, nudging, provision of incentives, withholding of financial benefits, imposition of financial penalties, withholding of social services and goods (e.g., enrolment in state school and day care; also known as mandatory vaccination), and, as a last resort, compulsory vaccination.

\section{REFERENCES}

Abrevaya, J., \& Mulligan, K. (2011). Effectiveness of State-Level Vaccination Mandates: Evidence from the Varicella Vaccine. Journal of Health Economics, 30(5), 966-976.

Beauchamp, T. L. \& Childress, J. F. (2001). Principles of Biomedical Ethics. Oxford: Oxford University Press.

Blumenthal-Barby, J. S., \& Burroughs, H. (2012). Seeking Better Health Care Outcomes: The Ethics of Using the "Nudge". The American Journal of Bioethics: AJOB, 12(2), 1-10.

Brewer, N. T., Gottlieb, S. L., Reiter, P. L., McRee, A.-L., Liddon, N., Markowitz, L., \& Smith, J. S. (2011). Longitudinal Predictors of Human Papillomavirus Vaccine Initiation Among Adolescent Girls in a High-Risk Geographic Area. Sexually Transmitted Diseases, 38(3), 197-204.

Brewer, N. T., Chapman, G. B., Rothman, A. J., Leask, J., \& Kempe, A. (2017). Increasing Vaccination: Putting Psychological Science into Action. Psychological Science in the Public Interest: A Journal of the American Psychological Society, $18(3), 149-207$.

California Department of Public Health. (2017). 2016-2017 Kindergarten Immunization Assessment - Executive Summary. Retrieved April 2018, from http://eziz.org/assets/docs/shotsforschool/2016-17KindergartenSummaryReport.pdf

Chandir, S., Khan, A. J., Hussain, H., Usman, H. R., Khowaja, S., Halsey, N. A., \& Omer, S. B. (2010). Effect of Food Coupon Incentives on Timely Completion 
of DTP Immunization Series in Children from a low-Income Area in Karachi, Pakistan: A Longitudinal Intervention Study. Vaccine, 28(19), 3473-3478.

Childress, J. F., Faden, R. R., Gaare, R. D., Gostin, L. O., Kahn, J., Bonnie, R. J., et al. (2002). Public Health Ethics: Mapping the Terrain. The Journal of Law, Medicine E Ethics: A Journal of the American Society of Law, Medicine \& Ethics, 30(2), 170-178.

Clarke, S., Giubilini, A., \& Walker, M. J. (2017). Conscientious Objection to Vaccination. Bioethics, 31(3), 155-161.

Colgrove, J. 2016. Vaccine Refusal Revisited-The Limits of Public Health Persuasion and Coercion. New England Journal of Medicine 375, 1316-1317. https://doi.org/10.1056/NEJMpl608967

Dubé, E., Laberge, C., Guay, M., Bramadat, P., Roy, R., \& Bettinger, J. (2013). Vaccine Hesitancy: An Overview. Human Vaccines \& Immunotherapentics, $9(8)$, 1763-1773.

Faden, R. R., \& Beauchamp, T. L. (1986). A History and Theory of Informed Consent. New York: Oxford University Press.

Faden, R. R., \& Faden, A. I. (1978). The Ethics of Health Education as Public Health Policy. Health Education Monographs, 6(2), 180-197.

Feinberg, J. (1989). The Moral Limits of the Criminal Law: Volume 3: Harm to Self. New York: OUP.

Flanigan, J. (2014). A Defense of Compulsory Vaccination. HEC Forum: An Interdisciplinary Journal on Hospitals' Ethical and Legal Issues, 26( 1), 5-25.

Frankfurt, H. (1973). Coercion and Moral Responsibility. In T. Honderich (Ed.), Essays on Freedom of Action. London: Routledge and Kegan Paul.

Fryer, R. G. (2013). Teacher Incentives and Student Achievement: Evidence from New York City Public Schools. Journal of Labor Economics, 31(2), 373-407.

Gneezy, U., Meier, S., \& Rey-Biel, P. (2011). When and Why Incentives (Don't) Work to Modify Behavior. The Journal of Economic Perspectives: A Journal of the American Economic Association, 25(4), 191-210.

Gostin, L. 2008. Public Health Law. Power, Duty, Restraint. Revised and Expanded (2nd ed.). Berkeley/Los Angeles: California University Press.

Green, L. W. (1978). Determining the Impact and Effectiveness of Health Education as It Relates to Federal Policy. Health Education Monographs, 6(Supplement 1). Retrieved from https://eric.ed.gov/?id=ED183498

Grill, K. (2017). Incentives, Equity and the Able Chooser Problem. Journal of Medical Ethics, 43(3), 157-161.

Halpern, S. D., Ubel, P. A., \& Asch, D. A. (2007). Harnessing the Power of Default Options to Improve Health Care. The New England Journal of Medicine, 357(13), 1340-1344.

Hausman, D. M., \& Welch, B. (2010). Debate: To Nudge or Not to Nudge. The Journal of Political Philosophy, 18(1), 123-136.

Held, V. (1972). Coercion and Coercive Offers. In J. R. Pennock \& J. W. Chapman (Eds.), Nomos XIV: Coercion (Vol. 14, pp. 49-62). Chicago: Aldine-Atherton. 
Hetherington, A. (1999). The Real Distinction Between Threats and Offers. Social Theory and Practice, 25(2), 211-242.

Hough-Telford, C., Kimberlin, D. W., Aban, I., Hitchcock, W. P., Almquist, J., Kratz, R., \& O'Connor, K. G. (2016). Vaccine Delays, Refusals, and Patient Dismissals: A Survey of Pediatricians. Pediatrics, 138(3). https://doi. org/10.1542/peds.2016-2127.

Jarrett, C., Wilson, R., O'Leary, M., Eckersberger, E., Larson, H. J., \& Others. (2015). Strategies for Addressing Vaccine Hesitancy-A Systematic Review. Vaccine, 33(34), 4180-4190.

Johnston, J. M., \& Sherman, R. A. (1993). Applying the Least Restrictive Alternative Principle to Treatment Decisions: A Legal and Behavioral Analysis. The Behavior Analyst, 16(1), 103-115.

Kahneman, D., Knetsch, J. L., \& Thaler, R. H. (1991). Anomalies: The Endowment Effect, Loss Aversion, and Status Quo Bias. The Journal of Economic Perspectives: A Journal of the American Economic Association, 5(1), 193-206.

Krubiner, C. B., \& Merritt, M. W. (2017). Which Strings Attached: Ethical Considerations for Selecting Appropriate Conditionalities in Conditional Cash Transfer Programmes. Journal of Medical Ethics, 43(3), 167-176.

Lagarde, M., Haines, A., \& Palmer, N. (2007). Conditional Cash Transfers for Improving Uptake of Health Interventions in Low- and Middle-Income Countries: A Systematic Review. JAMA: The Journal of the American Medical Association, 298(16), 1900-1910.

Li, M., \& Chapman, G. B. (2013). Nudge to Health: Harnessing Decision Research to Promote Health Behavior. Social and Personality Psychology Compass, 7(3), 187-198.

Lunze, K., \& Paasche-Orlow, M. K. (2013). Financial Incentives for Healthy Behavior: Ethical Safeguards for Behavioral Economics. American Journal of Preventive Medicine, 44(6), 659-665.

Lynch, H. F. (2016). Introduction. In G. Cohen, H. F. Lynch, \& C. Robertsonm (Eds.), Nudging Health: Health Law and Behavioural Economics (pp. 109111). Baltimore: Johns Hopkins University Press.

Marteau, T. M., Ashcroft, R. E., \& Oliver, A. (2009). Using Financial Incentives to Achieve Healthy Behaviour. BMJ, 338, b1415.

Miller, R. D. (1982). The Least Restrictive Alternative: Hidden Meanings and Agendas. Community Mental Health Journal, 18(1), 46-55.

Navin, M. C. (2017). The Ethics of Vaccination Nudges in Pediatric Practice. HEC Forum: An Interdisciplinary Journal on Hospitals' Ethical and Legal Issues, 29(1), 43-57.

Navin, M. C., \& Largent, M. A. (2017). Improving Nonmedical Vaccine Exemption Policies: Three Case Studies. Public Health Ethics, 10(3), 225-234.

Novemsky, N., \& Kahneman, D. (2005). The Boundaries of Loss Aversion. JMR, Journal of Marketing Research, 42(2), 119-128. 
Nozick, R. (1969). Coercion. In S. Morgenbesser, P. Suppes, \& M. White (Eds.), Philosophy, Science, and Method: Essays in Honor of Ernest Nagel (pp. 440-472). New York: St Martin's Press.

Nuffield Council on Bioethics. (2007). Public Health: Ethical Issues. Cambridge: Cambridge Publishers Ltd.

Nyhan, B., Reifler, J., Richey, S., \& Freed, G. L. (2014). Effective Messages in Vaccine Promotion: A Randomized Trial. Pediatrics, 133(4), e835-e842.

O'Neill, O. (1991). Which Are the Offers You Can't Refuse? In R. Frey \& C. Morris (Eds.), Violence, Terrorism, and Justice (pp. 170-195). Cambridge: Cambridge University Press.

Opel, D. J., Heritage, J., Taylor, J. A., Mangione-Smith, R., Salas, H. S., Devere, V., et al. (2013). The Architecture of Provider-Parent Vaccine Discussions at Health Supervision Visits. Pediatrics, 132(6), 1037-1046.

Pierik, R. (2016). Mandatory Vaccination: An Unqualified Defence. Journal of Applied Philosophy. https://doi.org/10.1111/japp.12215.

Ploug, T., \& Holm, S. (2015). Doctors, Patients, and Nudging in the Clinical Context-Four Views on Nudging and Informed Consent. The American Journal of Bioethics: AJOB, 15(10), 28-38.

Ranganathan, M., \& Lagarde, M. (2012). Promoting Healthy Behaviours and Improving Health Outcomes in Low and Middle Income Countries: A Review of the Impact of Conditional Cash Transfer Programmes. Preventive Medicine, 55(Suppl), S95-S105.

Rawls, J. (1971). A Theory of Justice: Revised 2009 Edition. Cambridge, MA: Harvard University Press.

Rossi, J., \& Yudell, M. (2012). The Use of Persuasion in Public Health Communication: An Ethical Critique. Public Health Ethics, 5(2), 192-205.

Saghai, Y. (2013). Salvaging the Concept of Nudge. Journal of Medical Ethics, $39(8), 487-493$.

Saghai, Y. (2014). Radically Questioning the Principle of the Least Restrictive Alternative: A Reply to NirEyal': Comment on "Nudging by Shaming, Shaming by Nudging". International Journal of Health Policy and Management, 3, 349-350.

Salmon, D. A., Moulton, L. H., Omer, S. B., DeHart, M. P., Stokley, S., \& Halsey, N. A. (2005). Factors Associated with Refusal of Childhood Vaccines Among Parents of School-Aged Children: A Case-Control Study. Archives of Pediatrics \& Adolescent Medicine, 159(5), 470-476.

Thaler, R., \& Sunstein, C. (2008/2009). Nudge. Improving Decisions About Health, Wealth, and Happiness. London: Penguin.

Verweij, M., \& Dawson, A. (2004). Ethical Principles for Collective Immunisation Programmes. Vaccine, 22(23-24), 3122-3126.

Voigt, K. (2017). Too Poor to Say No? Health Incentives for Disadvantaged Populations. Journal of Medical Ethics, 43(3), 162-166. 
Wang, E., Clymer, J., Davis-Hayes, C., \& Buttenheim, A. (2014). Nonmedical Exemptions from School Immunization Requirements: A Systematic Review. American Journal of Public Health, 104(11), e62-e84.

Warwick, D. P., \& Kelman, H. C. (1973). Ethical Issues in Social Intervention. In G. Zaltman (Ed.), Processes and Phenomena of Social Change. Hoboken: Wiley. Wertheimer, A. (1989, April). Review of Coercion (1987), by R. Nozick. Ethics, 99,642 .

WHO. (2014). Report of the SAGE Working Group on Vaccine Hesitancy. Retrieved April 2018, from http://www.who.int/immunization/sage/meetings/2014/october/1_Report_WORKING_GROUP_vaccine_hesitancy_ final.pdf

Wigham, S., Ternent, L., Bryant, A., Robalino, S., Sniehotta, F. F., \& Adams, J. (2014). Parental Financial Incentives for Increasing Preschool Vaccination Uptake: Systematic Review. Pediatrics, 134(4), el117-el128.

Yamin, D., \& Gavious, A. (2013). Incentives' Effect in Influenza Vaccination Policy. Management Science, 59(12), 2667-2686.

Yaqub, O., Castle-Clarke, S., Sevdalis, N., \& Chataway, J. (2014). Attitudes to Vaccination: A Critical Review. Social Science \& Medicine, 112, 1-11.

Zamir, E. (2015). Law, Psychology, and Morality: The Role of Loss Aversion. Oxford: Oxford University Press.

Open Access This chapter is licensed under the terms of the Creative Commons Attribution 4.0 International License (http://creativecommons.org/licenses/ by $/ 4.0 /)$, which permits use, sharing, adaptation, distribution and reproduction in any medium or format, as long as you give appropriate credit to the original author(s) and the source, provide a link to the Creative Commons license and indicate if changes were made.

The images or other third party material in this chapter are included in the chapter's Creative Commons license, unless indicated otherwise in a credit line to the material. If material is not included in the chapter's Creative Commons license and your intended use is not permitted by statutory regulation or exceeds the permitted use, you will need to obtain permission directly from the copyright holder.

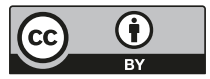

